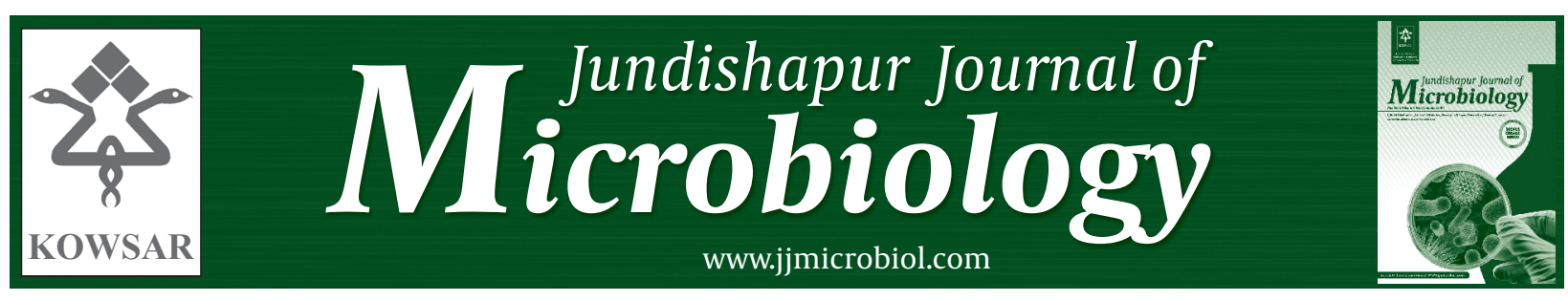

\title{
Investigation of Probiotic Chocolate Effect on Streptococcus mutans Growth Inhibition
}

\author{
Anita Khanafari ${ }^{1}$, Sepideh Hosseini Porgham ${ }^{1}$, Maryam Tajabadi Ebrahimi ${ }^{2}$ \\ ${ }^{1}$ Department of Microbiology, North Tehran Branch, Islamic Azad University, Tehran, IR Iran \\ ${ }^{2}$ Department of Microbiology, Central Tehran Branch, Islamic Azad University, Tehran, IR Iran
}

\begin{tabular}{l}
\hline A R T I C L E I N F O \\
\hline Article type: \\
Original Article \\
\hline Article history: \\
Received: 19 Dec 2011 \\
Revised: 23 Feb 2012 \\
Accepted: 09 Apr 2012
\end{tabular}

\begin{abstract}
A B S T R A C T
Background: One of the most important factors in inducing the logarithmic growth of Streptococcus mutans, is a diet containing fermentable carbohydrates such as sucrose. objectives: The aim of the current research was to compare the ability of ordinary and probiotic chocolate to induce or inhibit the growth of S. mutans.

Materials and Methods: Lactobacillus rhamnosus, L. plantarum and L. acidophilus as probiotic strains, were cultivated on MRS agar for 24 hours at $35^{\circ} \mathrm{C}$ in $5 \% \mathrm{CO}_{2}$. S. mutans which is a dominant factor in causing dental plaque, was isolated from 20 samples of dental plaque and caries lesions in adults on Streptococcus selective agar medium, and diagnosed by routine biochemical tests. The antimicrobial effect of three probiotic strains on S. mutans was evaluated by the deferred cross-streak method and susceptibility through the disk diffusion test. The antimicrobial effect of the probiotic supernatant powder was determined by a dilution method. Probiotic strains were added to dark chocolate with a concentration of $10^{8} \mathrm{CFU} / \mathrm{mL}$ and their antimicrobial effect on $S$. mutans was evaluated by the disk diffusion susceptibility method. Survival of the probiotic strains in chocolate and $\mathrm{pH}$ shifts were studied in different environmental storage conditions.

Results: The results showed that S. mutans was the dominant strain in all of the 20 dental plaque samples. L. plantarum showed the most antimicrobial effect on S. mutans with the maximum diameter of growth inhibitory zone, $35 \mathrm{~mm}$ and $78 \times 78 \mathrm{~mm}$ in the disk diffusion method and deferred cross-streak method, respectively. Probiotic supernatant powder inhibited S. mutans strains in concentrations of 500-700 and $100-300 \mathrm{mg} / \mathrm{ml}$ at $\mathrm{t}=0$ and $\mathrm{t}=24$, respectively. Comparing the results in terms of maintenance and storage of probiotic chocolate, it showed that the best condition to keep this chocolate is at $4^{\circ} \mathrm{C}$ (refrigerated) with a probiotic survival of 25 to 30 days. The $\mathrm{pH}$ level during this period decreased from a $\mathrm{pH}$ of 5 to 4. Probiotic chocolate containing L. rhamnosus was shown to have the greatest antimicrobial effect on S. mutans with a maximum diameter of growth inhibitory zone of $75 \mathrm{~mm}$ during 59 days storage at an ambient temperature and $4^{\circ} \mathrm{C}$.

Conclusions: These results suggest that probiotic chocolate is able to inhibit the growth of S. mutans rather than ordinary chocolate.
\end{abstract}

Keywords:

Streptococcus mutans

Probiotics

Dental Caries

Published by Kowsar Corp, 2012. cc 3.0.

Implication for health policy/practice/research/medical education:

Use of probiotic foods like as probiotic chocolate could be decrease dental plaques production.

Please cite this paper as:

Khanafari A, Hosseini Porgham S, Tajabadi Ebrahimi M. Investigation of Probiotic Chocolate Effect on Streptococcus mutans Growth Inhibition. Jundishapur J Microbiol. 2012;5(4): 590-7. DOI: 10.5812/jjm.3861

* Corresponding author: Anita Khanafari, Department of Microbiology, North Tehran Branch, Islamic Azad University, Tehran, IR Iran. Tel: +98-2122950723, Fax: +98-21229497930, E-mail:a_khanafari@iau-tnb.ac.ir

DOI: $10.5812 / j \mathrm{jm} .4071$

(C) 2012 Ahvaz Jundishapur University of Medical Sciences; Published by Kowsar Corp.

This is an Open Access article distributed under the terms of the Creative Commons Attribution License (http://creativecommons.org/licenses/by/3.0), which permits unrestricted use, distribution, and reproduction in any medium, provided the original work is properly cited. 


\section{Background}

More than 1000 bacterial species have been identified from the human mouth. These microorganisms are easily grown and produce dental plaque in the mouth environment, due to the constant influx of nutrients through; saliva, food intake, warm temperatures and moisture. Dental plaque can be considered as a microbiota with approximately $4 \times 10^{10}$ organisms, consisting on average of more than 400 species in each gram of plaque removed from the teeth. These live together within a biofilm community through the exploitation of very specific ecological niches (1). Bacterial genera are pioneers in the creation of dental cavities and periodontal disease. Streptococcus spp., Actinomyces spp., Veillonella spp., Fusobacterium spp., Porphyromonas spp., Prevotella spp., Treponema spp., Neisseria spp., Haemophilus spp., Eubacterium spp., Lactobacillus spp., Bifidobacterium spp., Capnocytophaga spp., Peptostreptococcus spp., Staphylococcus spp., and Propionibacterium spp. are the predominant genera detected in the oral cavity. Diseases such as dental caries and periodontal disease are directly linked to oral microbiota (1).

Streptococcus mutans is the most commonly implicated initiator and plaque-resident bacterium, that begins demineralization and the metabolism of simple carbohydrates, this produces acid as a by-product, which leads to tissue loss and further bacterial penetration $(2,3)$. This bacterium is considered to be the initiator of biofilm formation by its adherence and accumulation on the tooth surface which is promoted by its synthesis of insoluble, extracellular polysaccharides. It also produces numerous bacteriocins that kill other species, favoring its own competition in dental biofilm, as it has a high efficiency in catabolizing carbohydrates and producing acids, and the ability to tolerate low $\mathrm{pH}$ (1).

Probiotic refers to microorganisms with a positive effect on health by assisting with food and nutrient digestion and having a direct antagonistic effect against specific groups of organisms to decrease their numbers or effect on their metabolism and to stimulate immunity (1, 4-6). Probiotics are added in a culture concentrate to products such as; beverages or food (e.g. fruit juice), inoculated into prebiotic fibers or milk-based dairy products (e.g. milk, milk drinks, yoghurt, yogurt drinks, cheese, kefir, bio-drinks), as concentrated and dried cells packaged as dietary supplements in non-dairy products, (e.g. Powders, capsules, gelatin tablets) $(5,7)$.

Several studies have shown that probiotic bacteria, are not only associated with intestinal health, but they can also affect a wide range of other health factors; oral ecology, anticariogenic effects, modulation of gut immunological mechanisms, mucin production, down-regulation of inflammatory responses, secretion of antimicrobial substances, competition with other flora, including potential pathogens by competitive blocking of adhesion sites at epithelial and mucosal surfaces, inhibition of epithelial invasion by the regulation of intestinal permeability, inhibition of pathogens, mucosal adherence and stimulation of immunoglobulin A production and the production of anti-microbial substances, such as organic acids, hydrogen peroxide and bacteriocins (5, 8-12).

All products, both food and beverages, which contain fermentable carbohydrates (sugars and some starches) have the potential to cause tooth decay. Chocolate, which contains carbohydrates are no more or less responsible for tooth decay than any other carbohydrate containing foods such as bread, raisins, crackers, and fruit. However, chocolate in the form in which it is usually consumed, milk chocolate or candy bars, contains large amounts of sugar which is a known cause of tooth decay and may well counteract the effects of antibacterial agents $(1,5,13)$. S. mutans being the sole target species in caries development, more efforts have been directed towards inhibiting the known mechanisms of caries development such as; use of antibacterial agents like fluoride treatment, polyphenols from plant stimulant beverages like cocoa, coffee, and tea to reduce biofilm formation and acid production by S. mutans and S. sanguinis. Sugar substitutes (e.g. sorbitol and xylitol) that are not fermented by oral bacteria and do not cause a fall in plaque $\mathrm{pH}$. Bacteriotherapy is a fascinating approach in oral infectious disease management (1).

\section{Objectives}

In this study, the potential of probiotic chocolate to inhibit the growth of S. mutans, which is a dominant factor causing dental plaque, was investigated.

\section{Materials and Methods}

This research was carried out in the Microbiology Laboratory, North Tehran Branch, Islamic Azad University, Tehran, Iran, during 2010 to 2011. All data reported in this study are from triplicate measurements.

\subsection{Bacterial Strains and Culture Conditions \\ 3.1.1. Probiotic Strains}

Three probiotic strains; Lactobacillus rhamnosus PTCC 1637, L. plantarum PTCC 1058 and L. acidophilus PTCC 1643, were obtained from the Persian Type Culture Collection (PTTC) of the Iranian Research Organization for Science and Technology in Tehran, Iran. Bacterial strains were cultivated in (Fluka and Catalogue no.69966, Sigma-Aldrich) for 24 hours at $35^{\circ} \mathrm{C}$ in $5 \% \mathrm{CO}_{2}$ and $95 \%$ air atmosphere (14).

\subsubsection{Streptococcus mutans Strain}

S. mutans, a common dental plaque microorganism, was isolated from 20 samples of gingival dental plaque and caries lesions in adults which were obtained from the Sadeghieh Dental Center in Tehran under the supervision of qualified dentists and cultured on Streptococcus selective agar medium (Merck, Germany) and incubated at $35^{\circ} \mathrm{C}$ and $5 \% \mathrm{CO}_{2}$ for $48-72$ hours. Classic physiological 
characteristics were tested according to Bergey's Manual of Determinative Bacteriology (15).

\subsection{Bacterial Inoculum Cultures}

Probiotic bacteria and S. mutans inoculum cultures were performed in de Man, Rogosa and Sharpe (MRS) broth medium and Streptococcus selective broth medium, respectively and incubated at $35^{\circ} \mathrm{C}$ and $5 \% \mathrm{CO}_{2}$ for 48-72 hours. Bacterial cell density was adjusted on 0.2 at $600 \mathrm{~nm}$ (equal to $1 \times 10^{6} \mathrm{CFU} / \mathrm{mL}$ ) for probiotic bacteria and 0.6 at $600 \mathrm{~nm}$ (equal to $1 \times 10^{7} \mathrm{CFU} / \mathrm{mL}$ ) for S. mutans samples by UV-VIS scanning spectrophotometer, UV 2101 pc, Shimadzu (16).

\subsection{Antimicrobial Tests}

Antimicrobial activities of the probiotic bacteria strains and their dried supernatant on isolated S. mutans strains were evaluated by the deferred cross-streak technique and serial broth dilution method, respectively as follow's:

\subsection{Deferred Cross - Streak Technique}

According to Fang et al.1996, probiotic strain inoculum (equal to $1 \times 10^{6} \mathrm{CFU} / \mathrm{mL}$ ) were streaked on the center of the MRS agar plates covering a $1 \times 2 \mathrm{~cm}$ area and incubated at $35^{\circ} \mathrm{C}$ and $5 \% \mathrm{CO}_{2}$ for $48-72$ hours. This area was removed after bacterial growth and incubated over chloroform for one hour to inactivate any remaining cells and air dried for $45 \mathrm{~min}$. The plate was inoculated with $100 \mu \mathrm{l}$ of S. mutans tested at $107 \mathrm{CFU} / \mathrm{mL}$ and incubated at $35^{\circ} \mathrm{C}$ for 24 hours, then the inhibition zone around the probiotic growth was measured (17).

\subsection{Serial Broth Dilution Method}

Probiotic strains were cultured in MRS broth medium and incubated at $35^{\circ} \mathrm{C}$ and $5 \% \mathrm{CO}_{2}$ for 24 hours. Probiotic supernatant powders were obtained by centrifuging at 10000 rpm for 10 min and dried at $59^{\circ} \mathrm{C}$ (18). Serial dilutions of probiotic supernatant powder were prepared from 100 to 800 $\mathrm{mg} / \mathrm{mL}$ in MRS broth medium, $1 \mathrm{~mL}$ of $S$. mutans inoculum was added and incubated at $35^{\circ} \mathrm{C}$ and $5 \% \mathrm{CO}_{2}$ for 24 hours. Minimum inhibitory concentration (MIC) and minimum bactericidal concentration (MBC) effect of the probiotic supernatant powder was evaluated on S. mutans by culturing each dilution in MRS agar medium by the pour plate culture method and incubated at $35^{\circ} \mathrm{C}$ for 24 hours (19).

\subsection{Preparation of Probiotic Chocolate}

According to the WHO/FDA, probiotic bacteria should be present at $108 \mathrm{CFU} / \mathrm{g}$ in probiotic food substances (20). $100 \mathrm{~mL}$ of probiotic bacteria inoculum with $108 \mathrm{CFU} / \mathrm{mL}$ (according to McFarland 0.5) was added to $100 \mathrm{~g}$ of $68 \%$ dark chocolate (chocolate without any milk or nutrition bar, containing cocoa 55\%, cocoa butter 33\%, carbohydrate
$59.7 \mathrm{~g}$, calcium $98.17 \mathrm{mg}$, fat $31.2 \mathrm{~g}$, phosphorus $159.66 \mathrm{mg}$, protein $7.6 \mathrm{~g}$, iron $0.04 \mathrm{mg}$, copper $0.01 \mathrm{mg}$, zinc $0.23 \mathrm{mg}$ ) that was sterilized by alternatively heating it at $100^{\circ} \mathrm{C}$ in a bain-marie for 3 hours and then storing at $4^{\circ} \mathrm{C}$ for 24 hours (three days in total). The heated chocolate was cultured on MRS agar, blood agar and Eosin methylene blue agar EMB (Merck, Germany) and incubated at $35^{\circ} \mathrm{C}$ with and without $5 \% \mathrm{CO}_{2}$ for $24-48$ hours to ensure the absence of any microorganisms in the chocolate.

\subsection{Probiotic Chocolate Antimicrobial Effect on Strepto- coccus mutans}

The antimicrobial effect of the probiotic chocolate was evaluated by the disk diffusion susceptibility method (21). Blank discs were immersed in probiotic chocolate and the weight of the chocolate absorbed on each disc was calculated. Chocolate immersed discs were placed on MRS agar medium seeded with S. mutans strain inoculum culture and incubated at $35^{\circ} \mathrm{C}$ for 24 hours and the inhibition zone around the discs were examined.

\subsection{Survival of Probiotic Strains in Chocolate}

Three types of probiotic chocolate with three different storage conditions were prepared in order to evaluate the effects of different conditions on probiotic strains survival in chocolate. The first and second types of chocolate (in two series) were incubated at $35^{\circ} \mathrm{C}$ and $5 \% \mathrm{CO}_{2}$ for 15 days and 48 hours after inoculating probiotic strain suspensions respectively. The third type was incubated at room temperature for two hours. Then, the first and second series of each type were incubated at $4^{\circ} \mathrm{C}$ and $24^{\circ} \mathrm{C}$ (room temperature) respectively. Live bacterial cells were enumerated by two methods; colony counting and determining optical density by a spectrophotometer assay at $600 \mathrm{~nm}$. In the colony counting method, serial dilutions of probiotic chocolate were prepared in a physiological saline solution ( $8.5 \mathrm{~g} \mathrm{NaCl} / 1000 \mathrm{~mL}$ ), seeded in triplicate on agar MRS medium and incubated at $35^{\circ} \mathrm{C}$ and $5 \% \mathrm{CO}_{2}$ for 24-48 hours (13). Live cell numbers of probiotic bacteria were calculated using the following formula:

Live cells (CFU/g): number of colonies $\div$ (dilution factor $\times$ the amount used to make that pour plate)(22).

Degree of survival (\%) $=$ N/NO $\times 100$ [13]

Where:

$\mathrm{N}: \log$ CFU/g in the chocolate after the definite time of storage

No: $\log$ CFU/g in the newly produced chocolate

(In all of the cases No was equaled with $\log 108$ CFU per gram and $\mathrm{N}$ is the log of the number that resulted from the live cell formula).

To determine the degree of survival of probiotic bacteria after the pour plate, in which the probiotic chocolate was stored in ambient and refrigerated temperatures, all of the countable degrees of cell survival in which the di- 
lution of the pour plate were averaged and recorded as the total degree of cell survival.

\subsection{Acidity Tests}

The $\mathrm{pH}$ changes in three types of probiotic chocolate, with three different storage conditions were determined by a $\mathrm{pH}$ meter (Mettler-Toledo, USA) (13).

\section{Results}

S. mutans as a common dental plaque microorganism with minor differences in biochemical tests was dominant in all 20 of the plaque samples. Four strains $(1,6,10,14)$, based on minor differences in biochemical tests were randomly selected and subsequent tests were focused on them (Table 1).S. mutans strains 12 and 14 were inhibited more than the other strains by probiotic strains in the deferred crossstreak method. The highest inhibitory effect on the four Streptococci strains was obtained by L. plantarum PTCC 1058 (Table 2). Probiotic supernatant powders completely eliminated S. mutans growth in concentrations 500-700 and 100$300 \mathrm{mg} / \mathrm{mL}$ at $\mathrm{t}_{0}$ and $\mathrm{t}_{24}$, respectively (Table 3). A supernatant powder of L. plantarum PTCC 1058 was more effective than the others and among selected Streptococci strains, strains 14 and 5 were more sensitive, while 1 and 12 were more resistant (Table 3).The results of the probiotic chocolate antimicrobial effect on selected S. mutans strains showed that probiotic chocolate containing L. rhamnosus PTCC 1637 had a significant effect on $S$. mutans strains 12 and 14 after storage in room temperature and $4^{\circ} \mathrm{C}$ for 59 days with a $75 \mathrm{~mm}$ inhibition zone (Figure and Table 4). Comparison of the inhibitory zones caused by the three strains of probiotics (L. plantarum PTCC 1058, L. rhamnosus PTCC 1637 and L. acidophilus PTCC 1643) and probiotic chocolate containing L. plantarum PTCC 1058, L. rhamnosus PTCC 1637 and L. acidophilus PTCC 1643, showed that the antimicrobial effect of probiotic chocolate was greater than either probiotic strain alone. Chocolate containing L. plantarum PTCC 1058 and L. acidophilus PTCC 1643 was more effective on S. mutans 14 and 12 (Table 5).

All of the results showed that the survival of L. plantarum PTCC 1058, L. rhamnosus PTCC 1637 and L. acidophilus PTCC 1643 in the chocolate was high.

The results concerning the survival of the probiotic bacterium, L. rhamnosus PTCC1637 in the third kind of chocolate, maintained under refrigerated conditions was higher than in the ambient condition. The total de-

\begin{tabular}{|c|c|c|c|c|c|c|c|c|c|c|c|}
\hline & Bile Esculin & Hemolysis & $\begin{array}{l}\text { Voges } \\
\text { Proskuer }\end{array}$ & $\begin{array}{l}\text { Methyl } \\
\text { Red }\end{array}$ & $\begin{array}{l}\text { Arginine De- } \\
\text { carboxylase }\end{array}$ & Catalase & Trehalose & Lactose & Mannitol & Sorbitol & $\mathrm{NaCl} 6.5 \%$ \\
\hline 1 & + & $\delta$ & + & + & - & - & + & + & + & + & - \\
\hline 2 & + & $\delta$ & + & - & - & - & + & + & - & - & + \\
\hline 3 & + & $\delta$ & + & - & - & - & + & + & + & - & + \\
\hline 4 & + & $\delta$ & + & + & - & - & + & + & + & + & - \\
\hline 5 & + & $\delta$ & + & - & - & - & + & + & + & + & - \\
\hline 6 & + & $\delta$ & + & + & - & - & + & + & - & + & - \\
\hline 7 & + & $\delta$ & - & + & - & - & + & + & + & + & - \\
\hline 8 & + & $\delta$ & + & + & - & - & + & + & + & + & - \\
\hline 9 & + & $\delta$ & + & + & - & - & + & + & + & + & - \\
\hline 10 & + & $\delta$ & + & + & - & - & + & + & + & + & - \\
\hline 11 & + & $\delta$ & + & + & - & - & + & + & + & + & - \\
\hline 12 & + & $\delta$ & + & + & - & - & + & + & + & - & - \\
\hline 13 & + & $\delta$ & + & - & - & - & + & + & + & + & - \\
\hline 14 & + & $\alpha$ & - & + & - & - & - & + & - & + & - \\
\hline 15 & + & $\alpha$ & - & + & - & - & + & + & - & + & - \\
\hline 16 & + & $\delta$ & + & + & - & - & + & + & + & + & - \\
\hline 17 & + & $\delta$ & + & + & - & - & + & + & + & + & - \\
\hline 18 & + & $\delta$ & + & + & - & - & + & + & + & + & - \\
\hline
\end{tabular}

\begin{tabular}{|c|c|c|c|}
\hline & \multicolumn{3}{|c|}{ Inhibition Zone, mm } \\
\hline & Lactobacillus acidophilus PTCC 1643 & Lactobacillus plantarum PTCC 1058 & Lactobacillus rhamnosus PTCC 1637 \\
\hline 1 & $50 \times 50$ & $78 \times 78$ & $40 \times 45$ \\
\hline 5 & $50 \times 50$ & $78 \times 78$ & $60 \times 65$ \\
\hline 12 & $70 \times 70$ & $78 \times 78$ & $65 \times 65$ \\
\hline 14 & $60 \times 60$ & $78 \times 78$ & $65 \times 65$ \\
\hline
\end{tabular}



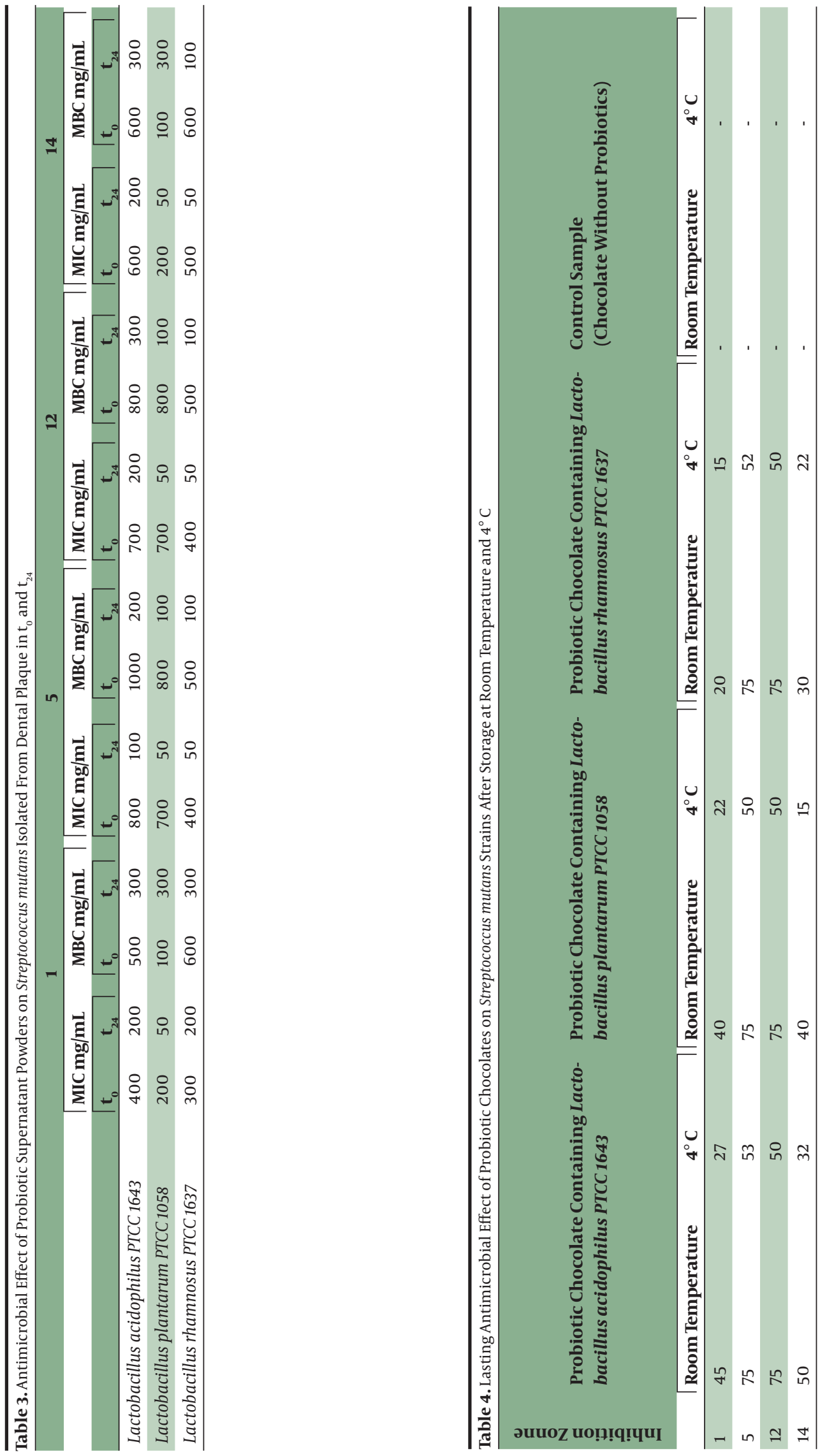


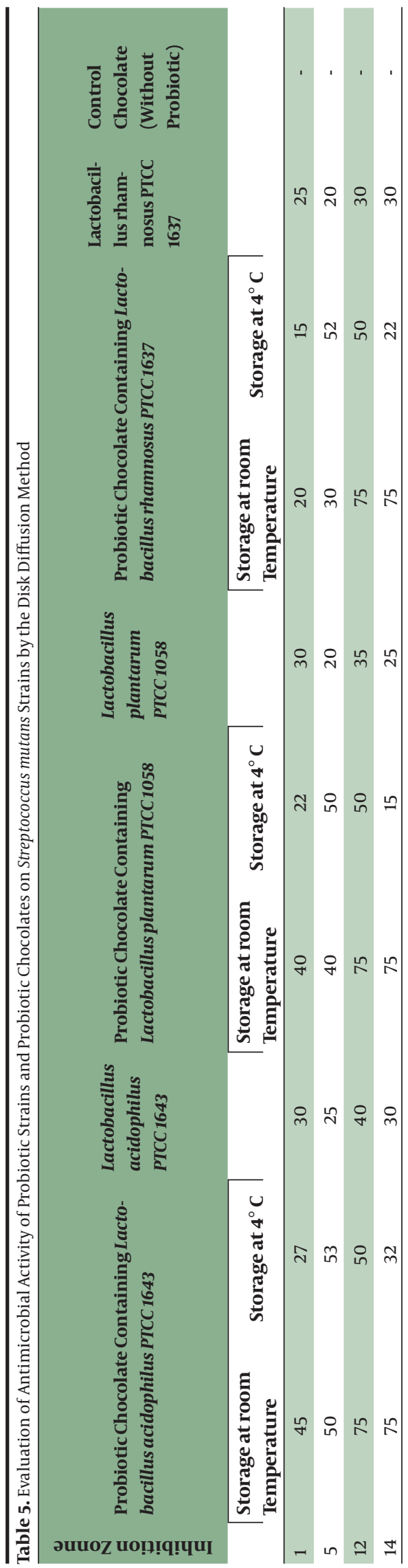

Figure. Disk Diffusion Susceptibility Method to Evaluate the Antimicrobial Effect of Probiotic Chocolate Containing Three Strains on Streptococcus mutans.

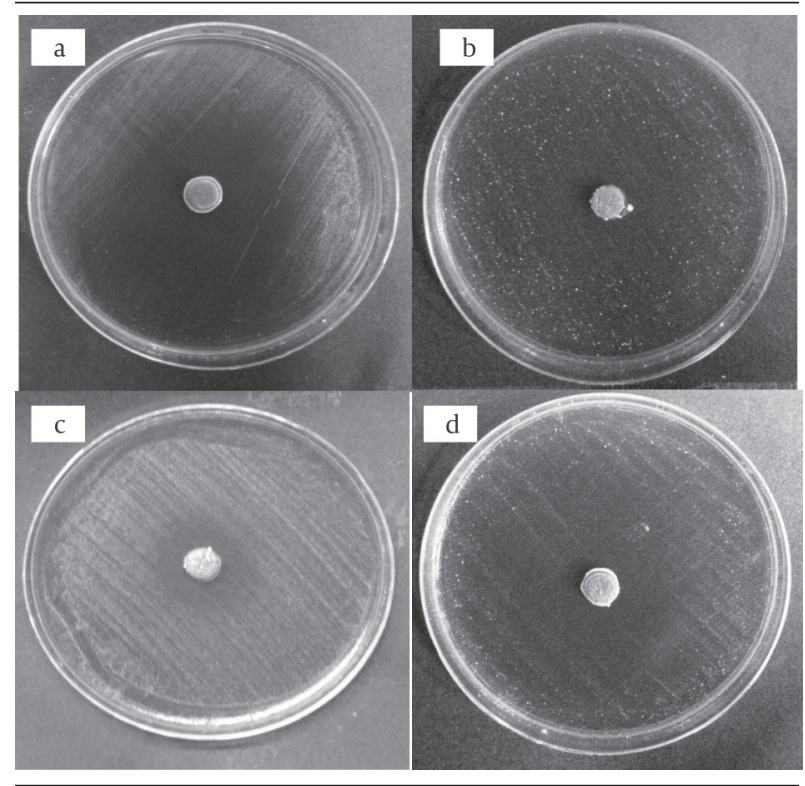

a) Probiotic chocolate containing L. plantarum PTCC 1058 and S. mutans five seeded; b) Probiotic chocolate containing L. rhamnosus PTCC 1637 and S. mutans one seeded; c) Probiotic chocolate containing L. rhamnosus PTCC 1637 and S. mutans five seeded; d) Probiotic chocolate containing L. acidophilus PTCC 1643 and S. mutans one seeded.

gree of survival of L. rhamnosus PTCC1637 cells after 25 days in the third chocolate in the refrigerated temperature was relatively higher (compared to the ambient temperature) and more than $105.05 \%$, the ultimate number of live cells ranged between $3 \times 10^{8}$ to $20 \times 10^{8} \mathrm{CFU} / \mathrm{g}$. The total degree of survival of L. rhamnosus PTCC1637 cells in this chocolate that were stored in ambient temperatures was determined to be $33.15 \%$ and the ultimate number of live cells evaluated ranged from $8 \times 10^{2}-10 \times 10^{2} \mathrm{CFU} / \mathrm{g}$. The results of the degree of cell survival in the two other probiotic chocolate were approximately similar to the third probiotic chocolate. All of the results that measured $\mathrm{pH}$ in terms of storage of the probiotic chocolate after approximately three months showed that it had decreased from a pH of 5 to 4 .

\section{Discussion}

Based on the development of functional foods such as probiotic chocolate and the acidifying properties of probiotic bacteria and their relationship with tooth decay, questions have arisen concerning the use of these foods. This research aimed to investigate the induction or reduction of $S$. mutans growth as it is a dominant bacterium producing dental plaque. In this research, S. mutans was isolated in all of the dental plaque samples, with only minor differences in biochemical tests. The antimicrobial effects of the probiotic bacteria were different on the four selected S. mutans strains. Among all of the probiotic 
strains, L. plantarum PTCC 1058 had the maximum antimicrobial effect on the $S$. mutans strains, with $S$. mutans strains 14 and 12 being more sensitive than the others.

Results showed that the range of effectiveness of the supernatant to eliminate $S$. mutans growth completely at $\mathrm{t}=0$ and $\mathrm{t}=24$, was between 500 to $700 \mathrm{mg} / \mathrm{mL}$ and 100 to $300 \mathrm{mg} / \mathrm{mL}$, respectively. According to Kang et al. (2010), studies on three strains of L. reuteri demonstrated a centrifuged supernatant inhibitory effect on periodontopathic and cariogenic bacteria, all three inhibited the growth of the periodontopathic bacteria and S. mutans by more than $90 \%$ (18). It is probably the production of some compounds such as bacteriocin or biosurfactant, which is the most likely reason for the antimicrobial effect of the supernatant probiotic powder. Several reports have documented the ability of probiotic bacteria to inhibit; cell association, colonization and invasion by pathogenic bacteria (17).

According to Bhushan and Chachra's (2010) research, some probiotic bacteria that express bacteriocins or bacteriocin-like inhibitory substances (BLIS), specifically prevent the growth of cariogenic bacteria. Some food grade and probiotic bacteria have the ability to colonize teeth and influence the growth of supragingival plaque. Some strains have been screened for suitable antagonistic activity against relevant oral bacteria (23). Adhesion reduction can be an effective way of decreasing the cariogenic potential of oral Streptococci (6). Some probiotic recombinant strains were able to express antibodies by targeting one of the major adhesions of S. mutans (antigen I/II) thus reducing both the viable counts of $S$. mutans and the caries score in a rat model (23).

The results of the current study showed that L. rhamnosus PTCC 1637 and L. acidophilus PTCC 1643 were less effective on four selected $S$. mutans strains than L. plantarum PTCC 1058. The results of the antimicrobial effects of chocolates containing probiotics such as L. plantarum PTCC 1058, L. acidophilus PTCC 1643 and L. rhamnosus PTCC 1637 showed that all three of the probiotic chocolates had a remarkable antimicrobial effect on S. mutans (Figure 1 and Table 4). Of the first and third probiotic chocolate containing L. rhamnosus PTCC 1637, the largest inhibitory zone was obtained on S. mutans 14 and 12, following 59 days storage in refrigerated and ambient temperatures. There is some evidence that $L$. rhamnosus does not readily ferment sucrose and is safer for the teeth than lactic acid producing bacteria (24). Most of the research has shown that this bacterium has a marked decreasing effect on the colonization of S. mutans (25).

Cocoa is believed to protect against various medical conditions, such as heart disease and cancer, as it is a rich source of catechins which are polyphenols of the flavanol group (26). Flavonoid structure has antibacterial activity. Several researchers have demonstrated a synergy between active flavonoids and chemotherapeutics (27).
The results of the second probiotic chocolate including L. acidophilus PTCC 1643 and L. plantarum PTCC 1058 (after 17 days stored in the refrigerator and ambient conditions), showed the biggest inhibitory zone was caused by probiotic chocolate containing L. plantarum PTCC 1058 on strains 14 and $12(75 \mathrm{~mm})$ and the smallest inhibitory zone was evaluated on strains 1 and $5(40 \mathrm{~mm})$. Some integrants in various chocolates such as inulin (prebiotic) or the probiotic strain Bifidobacterium sp., or a combination of these (synbiotics) can influence and selectively support the growth of probiotic strains which are conducive to inhibiting the growth of human fecal bacteria such as Salmonella sp and Enterococcus faecalis with their antibacterial effects (28). The results of probiotic bacteria survival in the different chocolate conditions showed that the shelf-life of the first chocolate (containing L. rhamnosus PTCC 1637) in the refrigerated temperature is greater than at ambient temperatures. The best condition was obtained by keeping this chocolate at $4^{\circ} \mathrm{C}$ (refrigerated conditions) with a probiotic survival of 25 to 30 days.

According to Maillard and Landuyta (2008), one of the major challenges to incorporating probiotics into liquid chocolate and chocolate related products on an industrial scale, is that these products need to be maintained at a temperature that does not kill the probiotics. This requires a narrow temperature range lower than that normally used in chocolate manufacturing, making it difficult to achieve effective mixing and proper probiotic dispersion (29). All products containing probiotics, must be kept in a refrigerator in order to maintain their highest viable capacity. The expiry period for these products, either juice or nutrition bar, is shorter than in products without probiotics (30).

It is important that the probiotic is added to the product in the correct stage of growth (31). Bacteria in the logarithmic growth phase are more sensitive to environmental stress compared to the lag phase. Also, environmental factors play an important role in shifting the bacteria from the logarithmic phase to the stationary phase. With the offering of probiotic products in the market, consumers expect to gain beneficial effects from using these products. To achieve this goal, the probiotic bacteria must stay alive till the end of its expiry period (31). All of the results measuring $\mathrm{pH}$ in terms of storage of the probiotic chocolate after approximately three months showed that the $\mathrm{pH}$ during this term had decreased from a pH of 5 to 4 .

In conclusion, the results showed that probiotic strains and probiotic chocolate can inhibit the growth of oral isolates of $S$. mutans, but their capacity differed significantly between the various strains. Further clinical studies are needed to verify whether or not the observed differences can play an inhibiting role in the development of complex oral dental plaque and biofilm. 


\section{Acknowledgements}

The authors would like to thank Dr. Reza Marandi, University Vice-Chancellor, for facility research services.

\section{Financial Disclosure}

None declared.

\section{Funding Support}

This study was performed at the Microbiology Department, North Tehran Branch, Islamic Azad University and was supported by the Office of Graduate Studies. The authors are grateful to the Office for its support.

\section{References}

1. Stamatova I. Probiotic activity of Lactobacillus delbrueckii subsp. bulgaricus in the oral cavity. Helsinky: Helsinky; 2010.

2. Forssten SD, Bjorklund M, Ouwehand AC. Streptococcus mutans, caries and simulation models. Nutrients. 2010;2 (3):290-8.

3. Simon L. The Role of Streptococcus mutans and oral ecology in the formation of dental caries. Undergrad Res J. 2007;2:2.

4. Marsh P, Martin M. Oral Microbiology. Oxford: Wright; 1999.

5. Reddy JJ, Sampathkumar N, Aradhya S. Probiotics in dentistry: review of the current status. Rev Clín Pesq Odontol. 2010;6 (3):261-7.

6. Tahmourespour A, Kermanshahi RK. The effect of a probiotic strain (Lactobacillus acidophilus) on the plaque formation of oral Streptococci. Bosn J Basic Med Sci. 2011;11 (1):37-40.

7. Caglar E, Kargul B, Tanboga I. Bacteriotherapy and probiotics' role on oral health. Oral Dis. 2005;11 (3):131-7.

8. Cabrera C, Artacho R, Gimenez R. Beneficial effects of green tea--a review. J Am Coll Nutr. 2006;25 (2):79-99.

9. Haukioja A, Loimaranta V, Tenovuo J. Probiotic bacteria affect the composition of salivary pellicle and streptococcal adhesion in vitro. Oral Microbiol Immunol. 2008;23 (4):336-43.

10. Miles L. Are probiotics beneficial for health? Nutr Bull. 2007;32 (1):2-5.

11. Niel CWV. Probiotics: not just for treatment anymore. Pediatrics 2005;115 (1):174-7.

12. Saavedra JM, Abi-Hanna A, Moore N, Yolken RH. Long-term consumption of infant formulas containing live probiotic bacteria: tolerance and safety. Am J Clin Nutr. 2004;79 (2):261-7.

13. Żyżelewicz D, Nebesny E, Moty I, Libudz Z. Effect of milk chocolate supplementation with lyophilised Lactobacillus cells on its attributes. Czech J Food Sci. 2010;28 (5):392-406.

14. El-Nezami H, Kankaanpaa P, Salminen S, Ahokas J. Ability of dairy strains of lactic acid bacteria to bind a common food carcinogen, aflatoxin B1. Food Chem Toxicol. 1998;36 (4):321-6.

15. Holt JG, Krieg NR, Sneath PHA, Staley JT, Williams ST. Bergey's Manual of Determinative Bacteriology. Baltimore: Williams \& Wilkins; 1994.

16. Baron E, Finegold S. Bailey and Scott's Diagnostic Microbiology. St Lois: C.V. Mosby Company; 1990.

17. Verdenelli MC, Ghelfi F, Silvi S, Orpianesi C, Cecchini C, Cresci A. Probiotic properties of Lactobacillus rhamnosus and Lactobacillus paracasei isolated from human faeces. Eur J Nutr. 2009;48 (6):355-63.

18. Kang MS, Oh JS, Lee HC, Lim HS, Lee SW, Yang KH, et al. Inhibitory effect of Lactobacillus reuteri on periodontopathic and cariogenic bacteria. J Microbiol. 2011;49 (2):193-9.

19. Gudina EJ, Rocha V, Teixeira JA, Rodrigues LR. Antimicrobial and antiadhesive properties of a biosurfactant isolated from Lactobacillus paracasei ssp. paracasei A20. Lett Appl Microbiol. 2010;50 (4):419-24.

20. Kligler B, Cohrssen A. Probiotics. Am Fam Physician. 2008;78 (9):1073.

21. Cid SRC, Cruz MC, Faustino V, Tuazon AO. IN VITRO Study on the Antimicrobial activity of probiotic milk against common pediatric community acquired respiratory pathogens. PIDSP Journal. 2005;9 (2):25-9.

22. Reynolds J, Farinha M. Counting Bacteria. In: College R, editor.; 2005. p. 1-10.

23. Bhushan J, Chachra S. Probiotics-their role in prevention of dental caries. J Oral Health Com Dent. 2010;4 (3):78-82.

24. Charalampopoulos D, Rastall RA. Prebiotics and probiotics science and technology. Springer Verlag; 2009.

25. Mehanna N, Zaazou M, Ahmed B, El-Yazeed MA. Effect of some probiotic strains and meswak plant on certain oral pathogenic strains. Int J Academic Res. 2009;1 (2):128-32.

26. Roy H, Lundy S, Kalicki B. Cocoa olyphenols. Pennington Nutr Series. 2005;1:1-4.

27. Cushnie TP, Lamb AJ. Antimicrobial activity of flavonoids. Int J Antimicrob Agents. 2005;26 (5):343-56.

28. Bin Othaman A. In-Vitro Synergistic Effects between Bifidobacterium Pseudocatenulatum G4 and inulin on Human Gastrointestinal Tract Microbial Composition. Putra: University of Putra; 2009.

29. Maillard M, Landuyta A. Chocolate: an ideal carrier for probiotics. Agro Food. Industry Hi-Tec. 2008;19 (3):13-5.

30. Christopher M, Reddy VP, Venkateswarlu K. Viability during storage of two Bifidobacterium bifidum strains in set and stirred flavoured yoghurts containing whey protein concentrates. Nat Prod Rad. 2009;8:25-31.

31. Heller KJ. Probiotic bacteria in fermented foods: product characteristics and starter organisms. Am J Clin Nutr. 2001;73 (2 Suppl):374S-9S 